\title{
Simultaneous Estimation of Loteprednol Etabonate and Gatifloxacin in Pharmaceutical Dosage Form by UHPLC Method
}

\author{
PremakumariKB $^{\mathrm{a}^{*}}$, MuruganV $^{\mathrm{a}}$, Ezhilarasan $\mathrm{V}^{\mathrm{b}}$, Joseph SahayaRaj ${ }^{\mathrm{c}}$ \\ a. Department of Pharmaceutical Chemistry, Dayananda Sagar College of Pharmacy, Bangalore-560078, India \\ ${ }^{b .}$ Department of Bioanalytical, Lotus Labs, Bangalore, India \\ c. Department of Quality Control, Synthiya Research Laboratory, Pondicherry,India.
}

\begin{abstract}
A reverse phase ultra-high performance liquid chromatography (RP-UHPLC) method was developed and validated for the simultaneous estimation of Loteprednoletabonate (LOTE) and Gatifloxacin (GAT) in pharmaceuticaldosage form. The separation was carried on zorbax eclipse plus column $C_{18}(4.6 \times 50 \mathrm{~mm}, 1.8 \mu$ particle size) column with mobile phase ( $\mathrm{pH} 6.0$ withtriethylamine) containing Acetonitrile, Methanol and $0.02 \mathrm{M}$ potassiumdihydrogen phosphate in the ratio of 40:30:30 v/v/v with a flow rate of $0.7 \mathrm{~mL} / \mathrm{min}$ and $U \mathrm{~V}$ detection at $272 \mathrm{~nm}$. The linearity was found to be in range of 15.34-46.03 $\mu \mathrm{g} / \mathrm{mL}\left(R^{2}=0.999\right)$ and 24.94-74.81 $\mu \mathrm{g} / \mathrm{mL}\left(R^{2}=0.999\right)$ for GAT and LOTE respectively. The method has shown good, consistent recoveries for GAT 98.88-101.24\% and LOTE 98.42 - 100.94\% respectively. The method was found to be accurate, precise, specific, robust and linear for the determination of GAT and LOTE in pharmaceutical dosage form.
\end{abstract}

Keywords: Gatifloxacin, Loteprednol etabonate, RP-UPLC, ICH guidelines, Method validation.

\section{Introduction}
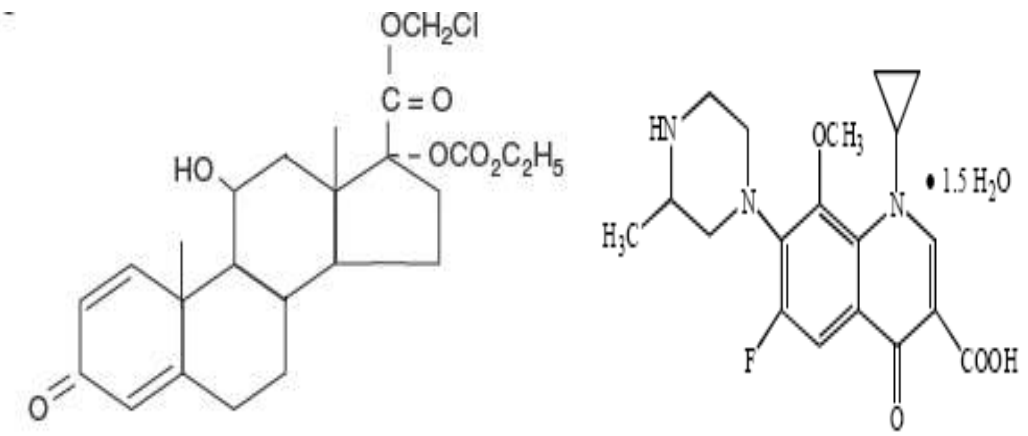

Figure 1: Structure of Loteprednol etabonate Figure 2: Structure of Gatifloxacin Sesquihydrate

Loteprednol etabonate is a topical corticosteroid anti-inflammatory. Chemically, it is chloromethyl 17ethoxycarbonyloxy-11-hydroxy-10,13-dimethyl-3oxo-7,8,9,11,12,14,15,16-octahydro-6H-cyclopenta phenanthrene-17-carboxylate. It is not an official compound in any pharmacopoeia. Literature survey reveals HPLC methods for the determination of LOTE in bile, blood and urine. To the best of our knowledge there is no UHPLC method reported for the simultaneous estimation of GAT and LOTE in ophthalmic dosage forms. Therefore, attempts were made in this study to develop a rapid, sensitive and selective RP-UHPLC method for the simultaneous determination of GAT and LOTE in combined dosage form as per ICH guidelines ${ }^{17}$. The chemical structure of LOTE was shown in figure 1.

Gatifloxacin sesquihydrate[1-cyclopropyl-6-fluoro-1,4-dihydro-8-methoxy-7-(3-methyl-1-piperazinyl)4-oxo-3-quinoline carboxylic acid], it is a synthetic broad spectrum antimicrobial fluoroquinolone that is active against both gram-negative and gram positive. From the literature available, it is noted that HPLC, HPTLC and UV spectrophotometric methods are described for GAT with other drugs in combination. The chemical structure of GAT was shown in figure 2.

\section{Chemicals and reagents}

\section{Experimental Details}

Loteprednol etabonate and Gatifloxacin were collected as a gift sample from Micro Labs Limited, Bangalore, India. All other chemicals required for the experiment were of HPLC grade and were purchased from MERCK chemicals. Chemicals used for this experiment were methanol, acetonitrile, water, triethylamine and potassium dihydrogen phosphate. 


\section{Instrument and chromatographic conditions}

Chromatography was performed on UPLC Agilent technologies. The chromatographic system equipped with 1220 infinity LC, auto sampler, binary solvent and UV detector. The chromatographicseparation was performed using zorbax eclipse plus column $\mathrm{C} 18$ (4.6x50mmx1.8 $\mu$ particle size).

Separation was achieved using a mobile phase consisting of acetonitrile, methanol and $0.02 \mathrm{M}$ potassium dihydrogen phosphate buffer (40:30:30v/v/v) adjusted to $\mathrm{pH} 6.0$ with triethylamine, pumped at a flow rate of $0.7 \mathrm{ml} / \mathrm{min}$. The eluent was monitored using UV detector at a wavelength of $272 \mathrm{~nm}$. The mobile phase was vacuum filtered through $0.22 \mu \mathrm{m}$ nylon membrane filter followed by degassing in an ultrasonic bath prior to use. Data acquisition and integration was performed using open lab CDS chemstation software.

Fig.3 Overlay spectra of LOTE and GAT

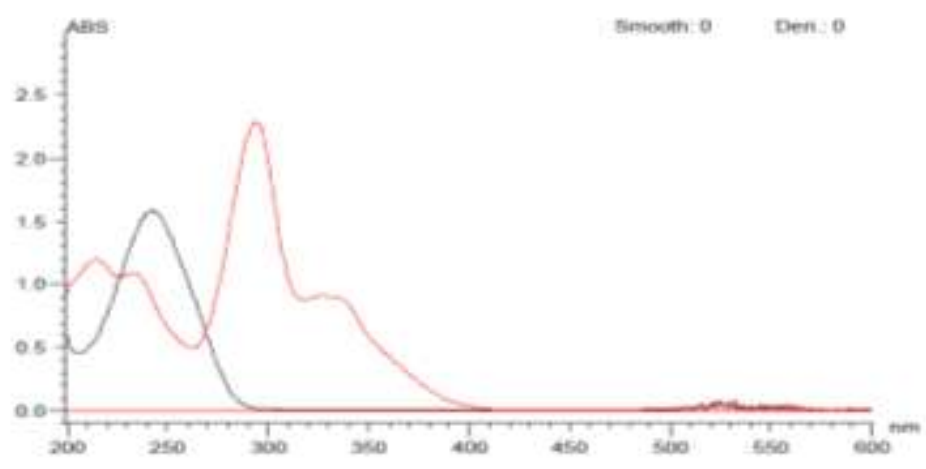

\section{Preparation of Mobile phase/Diluent}

A mixture of 30 volumes of $0.02 \mathrm{M}$ potassium dihydrogen orthophosphate previously adjusted to $\mathrm{pH}$ 6.0 with triethylamine, 30 volumes of methanol and 40 volumes of acetonitrile.

\section{Preparation of standard solution}

Weighed accurately about $15 \mathrm{mg}$ of Gatifloxacin working standard and $25 \mathrm{mg}$ Loteprednol working standard in $50 \mathrm{ml}$ volumetric flask. Dissolved with diluent, and diluted with mobile phase up to the mark. Pipetted out $5 \mathrm{ml}$ of this solution into $50 \mathrm{ml}$ volumetric flask, made up the volume with diluent to get $50 \mu \mathrm{g} / \mathrm{ml}$ and $30 \mu \mathrm{g} / \mathrm{ml}$.

\section{Sample preparation for calibration curve of GAT and LOTE}

Aliquots were taken from working standard solutionflask and diluted to $10 \mathrm{ml}$ with mobile phase to give final concentration of $15.34 \mu \mathrm{g} / \mathrm{ml}$ to $46.03 \mu \mathrm{g} / \mathrm{ml}$ for GAT and $24.94 \mu \mathrm{g} / \mathrm{ml}$ to $74.81 \mu \mathrm{g} / \mathrm{ml}$ for LOTE. Separatelyinjected the linearity solution in increasing concentration levels into the chromatograph and recorded the peak response.Calibration graph was constructed by plotting peak area versus concentration.

\section{Robustness}

Toevaluate LC method robustness, afew parameters were deliberately varied. The parameters included variation of flow rate, percentage of organic medium in the mobile phase and wavelength. One factor at a time was changed to estimate the effect. Thus 3 injections of standard solution was performed under small changes of three chromatographic parameters.

\section{Linearity}

The calibration curves constructed for GAT and LOTE were checked for linearity over the concentration range of $15.34 \mu \mathrm{g} / \mathrm{ml}$ to $46.03 \mu \mathrm{g} / \mathrm{ml}$ for GAT and $24.94 \mu \mathrm{g} / \mathrm{ml}$ to $74.81 \mu \mathrm{g} / \mathrm{ml}$ for LOTE. Calculated the correlationcoefficient.

\section{Accuracy}

The known quantity of the drug substance corresponding to $50,100,150 \%$ of standard GAT and LOTE and the mixture were analyzed by the proposed method. At each level of the amounts six determinations were performed. This was done to check the accuracy of the drug at different levels in the formulations.

\section{Precision}

Six injections of three different concentrations were given on the same day and the values of the \%RD were calculated to determine intra-day precision. Threeinjectionsof three different concentration were given on three different days to determine inter-day precision.

\begin{tabular}{llr}
\hline DOI: $10.9790 / 3008-1104018287$ & www.iosrjournals.org & $83 \mid$ Page
\end{tabular}




\section{Limit of quantitation (LOQ) and limit of detection (LOD)}

The LOQ and LOD were determined based on a signal-to-noise ratios and were based on analytical responses of 10 and 3 times the background noise respectively. LOD and LOQ were experimentally verified by diluting known concentration of GAT and LOTE until the average responses were approximately 3 or 10 times the standard deviation of the responses for six replicate determinations.

\section{Stability of solution}

Three different concentration of GAT and LOTE were prepared from sample solution and stored at room temperature for 6 hours and 24 hours at room temperature. They were then injected into HPLC system.

\section{Analysis of marketed and developed formulation of GAT and LOTE}

To determine the content of GAT and LOTE in formulations, $1 \mathrm{ml}$ of the sample was transferred into $10 \mathrm{ml}$ volumetric flask, dissolved with diluent. Filtered the solution through $0.45 \mu$ membrane filter. Then pipetted out $1 \mathrm{ml}$ of the above solution into $10 \mathrm{ml}$ volumetric flask, made up the volume with the diluent. The concentration of GAT and LOTE in sample stock solution was $30 \mu \mathrm{g} / \mathrm{ml}$ and $50 \mu \mathrm{g} / \mathrm{ml}$. The analysis was repeated in triplicate.

\section{Results And Discussion}

Validation of developed UPLC method was carried out as per ICH guidelines Q2 (R1). To develop an effective method for the analysis of the drugs, preliminary tests were performed in order to select adequate and optimum conditions. Parameters such as detection wavelength, ideal mobile phase and its combination, optimum $\mathrm{pH}$ and concentration of the standard solutions were studied. The mobile phase consisted of Acetonitrile: methanol: 0.02M potassium dihydrogen phosphate buffer (40:30:30 v/v/v) and adjusted the mobile phase to $\mathrm{pH} 6.0$ with triethylamine with a flow rate of $0.7 \mathrm{ml} / \mathrm{min}$ was selected for analysis after preliminary tests. The retention time of GAT and LOTE were found to be 1.34 and 3.31 min, respectively.

The System suitability tests were carried out on freshly prepared standard solutions and the \% RSD values were within the limit $(<2.0)$. The linearity was found in the concentration range of $15.34-46.03 \mu \mathrm{g} / \mathrm{ml}$ for GAT and 24.94-74.81 $\mu \mathrm{g} / \mathrm{ml}$ for LOTE. The correlation coefficient was found to be 0.999 and 0.999 for both the drugs respectively.The results are presented in table 3 and figure $4 \& 5$. The $\%$ accuracy was found between the range of $99.96-100.20$ for GAT and 99.37-100.14 for LOTE and represented in table 4. By performing system precision and method precision studies, the \% RSD values were within the limits $(<2.0)$ and the method was found to be highly precise and represented in table 5. Robustness of the method was studied by changing the chromatographic conditions slightly. Specificity was evaluated by injecting the blank, placebo and sample. There was no other interfering peak around the retention time of GAT and LOTE. So the proposed method was found to be simple, accurate and specific, hence it could be used for routine analysis of GAT and LOTE in combined dosage form.

Table 1 optimized parameters of UPLC method

\begin{tabular}{|l|l|}
\hline Column & Zorbax Eclipse Plus, C18 $(50 \mathrm{~mm} \times 4.6 \mathrm{~mm}, 1.8 \mu \mathrm{m})$ \\
\hline Mobile phase & $\begin{array}{l}\text { Acetonitrile:Methanol:0.02M dihydrogen orthophosphate } \\
\text { adjusted the } \mathrm{pH} \text { to } 6.0 \text { with triethylamine }(40: 30: 30 \mathrm{v} / \mathrm{v} / \mathrm{v}) .\end{array}$ \\
\hline Column tempt. & $30^{\circ} \mathrm{C}$ and sampler cooler $10^{\circ} \mathrm{C}$ \\
\hline Flow rate & $0.7 \mathrm{ml} / \mathrm{min}$ \\
\hline Flow & Isocratic \\
\hline Detection wavelength & $272 \mathrm{~nm}$ \\
\hline
\end{tabular}

Table 2 Robustness evaluation

\begin{tabular}{|l|l|l|l|l|}
\hline Parameter & Proposed & Variation & GAT & LOTE \\
\hline & & & $\%$ RSD & $\%$ RSD \\
\hline Wavelength & $272 \mathrm{~nm}$ & $270 \mathrm{~nm}$ & 0.61 & 0.91 \\
\hline & & $274 \mathrm{~nm}$ & 0.45 & 0.44 \\
\hline Flow Rate & $0.7 \mathrm{ml} / \mathrm{min}$ & $0.65 \mathrm{ml} / \mathrm{min}$ & 0.85 & 0.39 \\
\hline & & $0.75 \mathrm{ml} / \mathrm{min}$ & 0.21 & 0.81 \\
\hline Mobile Phase & $30: 30: 40 \mathrm{v} / \mathrm{v} / \mathrm{v}$ & $25: 30: 45$ & 0.24 & 0.41 \\
\hline & & $35: 30: 35$ & 0.44 & 0.97 \\
\hline
\end{tabular}


Table 3 Linearity of GAT and LOTE

\begin{tabular}{|c|c|c|c|}
\hline \multicolumn{2}{|c|}{ Concentration $(\boldsymbol{\mu g} / \mathbf{m l})$} & \multicolumn{2}{c|}{ Peak Area } \\
\hline GAT & LOTE & GAT & LOTE \\
\hline 15.34 & 24.94 & 117.47 & 27.43 \\
\hline 21.48 & 34.91 & 165.06 & 38.91 \\
\hline 24.55 & 39.90 & 190.92 & 43.94 \\
\hline 27.62 & 44.88 & 212.07 & 49.27 \\
\hline 30.69 & 49.87 & 238.00 & 55.04 \\
\hline 33.76 & 54.86 & 261.49 & 60.37 \\
\hline 36.83 & 59.84 & 285.14 & 65.59 \\
\hline 39.90 & 64.83 & 310.37 & 70.99 \\
\hline 46.03 & 74.81 & 357.73 & 82.00 \\
\hline \multicolumn{2}{|c|}{ Correlation coefficient } & $\mathbf{0 . 9 9 9}$ & $\mathbf{0 . 9 9 9}$ \\
\hline
\end{tabular}

Figure 4Calibration curve of Gatifloxacin

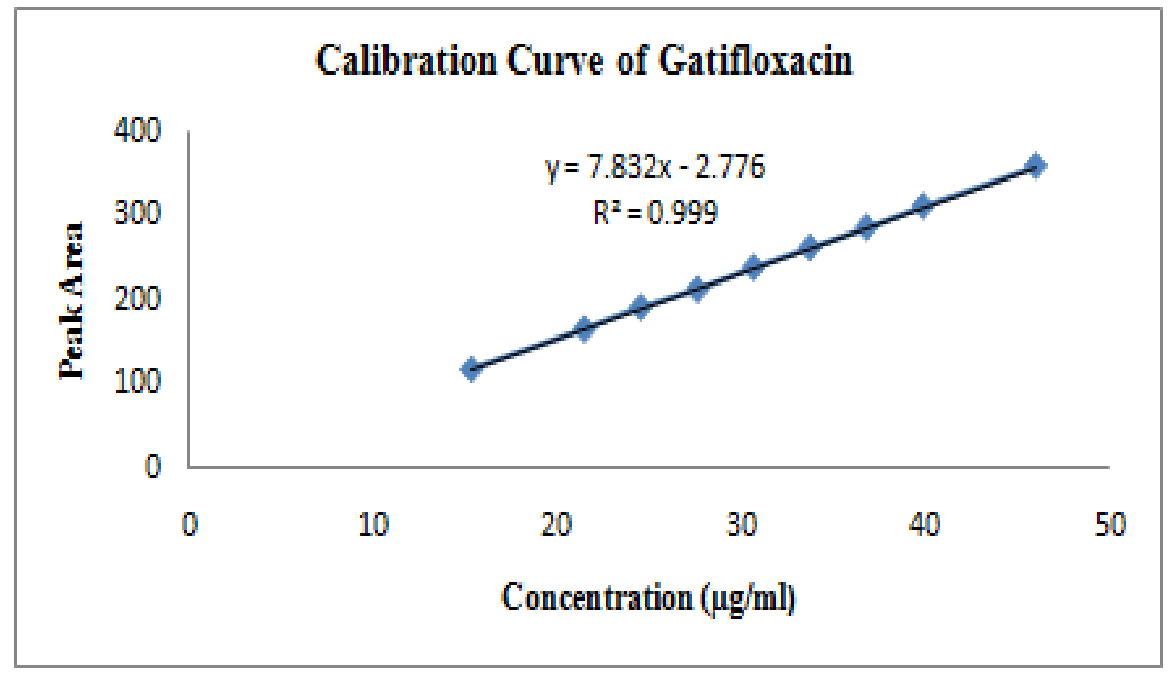

Figure 5Calibration curve of Loteprednol etabonate

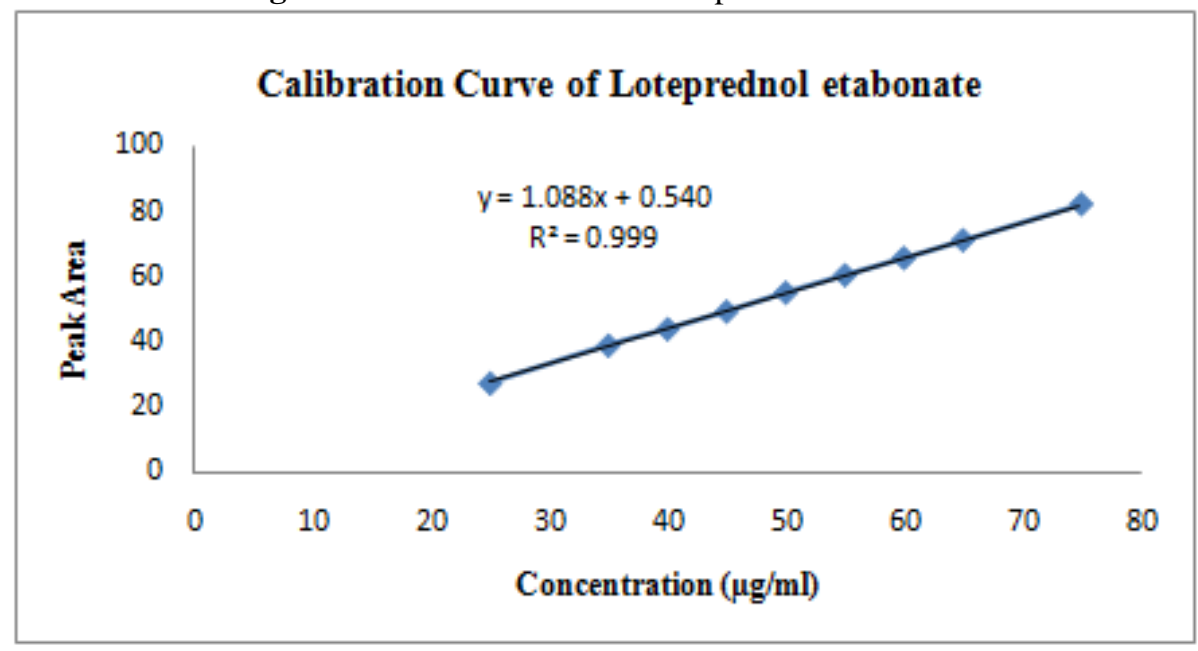

Table 4Accuracy

\begin{tabular}{|c|c|c|c|c|c|c|c|c|}
\hline S.No & \multicolumn{2}{|c|}{$\begin{array}{c}\text { Conc. of Std } \\
\text { spiked }\end{array}$} & \multicolumn{2}{c|}{$\begin{array}{c}\text { Amount added } \\
(\mathbf{m g} / \mathbf{1 0 0 m l})\end{array}$} & \multicolumn{2}{c|}{$\begin{array}{c}\text { Amount Recovered } \\
(\mathbf{m g} / \mathbf{1 0 0 m l})\end{array}$} & \multicolumn{2}{c|}{$* \%$ Recovery \pm SD } \\
\cline { 2 - 9 } & GAT & LOTE & GAT & LOTE & GAT & LOTE & GAT & LOTE \\
\hline 1 & 50 & 50 & 30.12 & 50.09 & 30.108 & 50.095 & $99.96 \pm$ & $100.01 \pm$ \\
& & & & & & & 0.16 & 0.23 \\
\hline 2 & 100 & 100 & 60.24 & 100.18 & 60.359 & 99.548 & $100.20 \pm$ & $99.37 \pm$ \\
& & & & & & & 0.35 & 0.25 \\
\hline 3 & 150 & 150 & 90.36 & 150.27 & 90.443 & 150.479 & $100.09 \pm$ & $100.14 \pm$ \\
& & & & & & & 0.35 & 0.56 \\
\hline
\end{tabular}


Table 5Precision

\begin{tabular}{|c|c|c|c|c|c|}
\hline \multirow[t]{2}{*}{ S.No } & \multirow[t]{2}{*}{ Sample } & \multicolumn{2}{|c|}{ GAT } & \multicolumn{2}{|c|}{ LOTE } \\
\hline & & Area & Assay \% & Area & Assay \% \\
\hline 1 & Low-1 & 149.37 & 99.53 & 34.37 & 99.96 \\
\hline 2 & Low-2 & 149.79 & 99.81 & 34.49 & 100.31 \\
\hline 3 & Low-3 & 148.87 & 99.20 & 34.09 & 99.15 \\
\hline 4 & Mid-1 & 245.68 & 98.22 & 57.12 & 99.68 \\
\hline 5 & Mid-5 & 246.60 & 98.59 & 57.11 & 99.66 \\
\hline 6 & Mid-6 & 249.01 & 99.55 & 56.93 & 99.35 \\
\hline 7 & High-1 & 355.93 & 101.64 & 79.40 & 98.97 \\
\hline 8 & High-2 & 350.21 & 100.01 & 80.27 & 100.05 \\
\hline 9 & High-3 & 350.14 & 99.99 & 80.19 & 99.95 \\
\hline \multicolumn{3}{|c|}{ Average : } & 99.54 & & 99.67 \\
\hline \multicolumn{3}{|c|}{ S.D. : } & 0.48 & & 0.18 \\
\hline \multicolumn{3}{|c|}{ \% R.S.D.: } & 0.76 & & 0.48 \\
\hline
\end{tabular}

\section{Limit of quantitation (LOQ) and limit of detection (LOD)}

The LOQ was found to be $12 \mu \mathrm{g} / \mathrm{mlfor}$ GAT and $20 \mu \mathrm{g} / \mathrm{ml}$ for LOTE. The LOD was found to be 2 $\mu \mathrm{g} / \mathrm{mlfor} \mathrm{GAT}$ and $5 \mu \mathrm{g} / \mathrm{ml}$ for LOTE.

\section{Stability in sample solutions}

No additional peak was found in chromatogram indicating the stability of LOTE and GAT in the sample solution.

\section{Analysis of marketed and developed formulations of LOTE and GAT}

The validated UPLC method was successfully applied for the assay of GAT and LOTE in marketed formulations. Assay results are represented in Table 6.

Table 6Assay of GAT and LOTE

\begin{tabular}{|c|c|c|c|c|c|c|}
\hline Drug & \multicolumn{2}{|c|}{$\begin{array}{c}\text { Label Claim } \\
(\% \text { w/v })\end{array}$} & \multicolumn{2}{c|}{$\begin{array}{c}\text { Amount found } \\
(\% \text { w/v })\end{array}$} & \multicolumn{2}{c|}{$\begin{array}{c}\text { * Label Claim } \\
\pm \text { S.D. }\end{array}$} \\
\hline \multirow{3}{*}{ Zylopred } & GAT & LOTE & GAT & LOTE & GAT & LOTE \\
\cline { 2 - 7 } & $\mathbf{0 . 3}$ & $\mathbf{0 . 5}$ & $\mathbf{0 . 3 0 1 1}$ & $\mathbf{0 . 4 9 8 2}$ & $\mathbf{1 0 0 . 3 6} \pm$ & $\mathbf{9 9 . 3 6} \pm$ \\
& & & & & 0.4806 & $\mathbf{0 . 1 7 3 8}$ \\
\hline
\end{tabular}

\section{System suitability}

This was performed by injecting six consecutive injections of solutions having concentration of 30.69 $\mu \mathrm{g} / \mathrm{ml}$ and $49.87 \mu \mathrm{g} / \mathrm{mlduring}$ the start of method validation and start of each day. Differentpeak parameters were observed like retention time, tailing factor, theoretical plates and \%RSD of area. These are summarised in Table 7.

Table 7 Summary of Validation Parameters

\begin{tabular}{|c|c|c|c|}
\hline \multicolumn{2}{|l|}{ Parameter } & Gatifloxacin & Loteprednol etabonate \\
\hline \multirow{3}{*}{$\begin{array}{l}\text { System } \\
\text { suitability }\end{array}$} & Tailing factor & 1.40 & 1.03 \\
\hline & Theoretical plates/meter & 1796 & 14336 \\
\hline & $\%$ RSD of 6 injections & 0.633 & 0.967 \\
\hline \multicolumn{2}{|c|}{ System Precision } & 0.633 & 0.967 \\
\hline \multicolumn{2}{|c|}{ Method Precision } & 0.76 & 0.48 \\
\hline \multicolumn{2}{|c|}{ Ruggedness } & 0.31 & 0.47 \\
\hline \multicolumn{2}{|c|}{ Accuracy (Mean) } & 99.40 & 99.53 \\
\hline \multicolumn{2}{|c|}{ Linearity (r2) } & 0.999 & 0.999 \\
\hline \multicolumn{2}{|c|}{ Robustness } & $\begin{array}{c}\text { Within Acceptance } \\
\text { criteria }\end{array}$ & $\begin{array}{c}\text { Within Acceptance } \\
\text { criteria }\end{array}$ \\
\hline \multicolumn{2}{|l|}{ Specificity } & $\begin{array}{l}\text { No interference due to } \\
\text { blank and placebo }\end{array}$ & $\begin{array}{c}\text { No interference due to } \\
\text { blank and placebo }\end{array}$ \\
\hline
\end{tabular}

\section{Conclusion}

UPLC method has been developed and validated for the determination of Gatifloxacin and Loteprednol etabonate in combined pharmaceutical dosage forms. The developed method was validated as per ICH guidelines and was found to be accurate, precise, robust, specific and less time consuming. No interference from any components of pharmaceutical dosage form observed, and the method has been successfully used to perform rapid and accurate analysis of Gatifloxacin and Loteprednol etabonatein their combined pharmaceutical dosage form. 


\section{Acknowledgement}

The authors are thankful to the Management and Principal of Dayananda Sagar College of Pharmacy, Bangalore and to Synthiya Research Laboratory, Pondicherry for providing all the facilities to carry out the research work.

\section{References}

[1]. www.unige.ch. web labo Davy Guillarme and Jean-Luc Veuthey. Guidelinesfor the use of UHPLC instruments.

[2]. ICH Q2 (R1), Validation of Analytialprocedures,Text and Methodology, International Conference on Harmonization. Geneva. 2005. p. 1-17.

[3]. Nagaraju P, Kiran kumar S, Poornima CH. Development and validation of RP-HPLC method for the simultaneous estimation of Brimonidinetartarate and timololmaleate in combined dosage form. Asian J Chem Pharm Res. 2014, 2(1), 58-64.

[4]. [4] RajaAbhilash P, Vasanthkumar K, Sateeshkumar V. Development and Validation of new RP-UPLC method for the quantitative analysis of Mycophenolate in tablet dosage form. British J Pharm Res. 2013, 3(3),363-73.

[5]. VaibhavSaxena, Anoop Singh. Development and Validation of HPLC method for the simultaneous estimation of Loteprednol and Gatifloxacin. Int J Sci Res. 2013, 2(5), 252-55.

[6]. Ameeduzzafar, Javed Ali, Asgar Al. Development and Validation of UPLC/ESI-Q-TOF-MS for carteolol in aqueous humour: Stability, stress degradation andapplication in pharmacokinetics of nano formulation. Arabian J Chem. 2013, 11(034), 1-9.

[7]. Pawan K Basniwal, Deepti Jain. ICH guideline practice: Application of novel RP-HPLC-DAD method for determination of Olapatadine hydrochloride in pharmaceutical products. J Anal Sci Tech. 2013, 12, 48-52.

[8]. Sharma N, Rao SS, Reddy AM. A novel and rapid validation stability-indicating UPLC method of related substances for dorzolamide hydrochloride and timololmaleate in ophthalmic dosage form. J chromatogra Sci. 2012, 50(9), $745-55$.

[9]. Roy C, Chakrabarty J, Mod PB. Validated stability-indicating reverse phase ultra-performance liquid chromatography method for simultaneous determination of sodium methyl paraben, sodium propyl paraben and ketorolac tromethamine in topical dosage form. Indian J Pharm Sci. 2013,75,197-204.

[10]. BatukDabhi, Bhaveshparmar, Nitish Patel, Yashwantsinhjadeja, Madhavipatel.UPLC method for the determination of Levofloxacin hemihydrate in pharmaceutical dosage form:Application to pharmaceutical Analysis.Chromatograph Res Int.2013, 1-5.

[11]. YarramRamakoti Reddy, Kakumani Kishore Kumar, MRP Reddy, Mukkanti. RP-UPLC method development and validation for the simultaneous estimation of Ibuprofen and famotidine in pharmaceutical dosage form. Pharm Methods. 2012, 3(2),57-61. 